\title{
Comunicação, Ideologia e Ciência: questões epistemológicas e metodológicas
}

\author{
Rakel de Castro \& Heitor Costa Lima da Rocha \\ Universidade Federal de Pernambuco \\ E-mail: patriciascastro@hotmail.com/hclrocha@gmail.com
}

\begin{abstract}
Resumo
Este artigo faz um review crítico-interpretativo tentando estabelecer uma relação entre a Comunicação e a Ciência, tomando por base algumas características comuns a ambas manifestações humanas como a concretização da linguagem e o caráter opaco/ideológico, utilizando concepções críticas de Wittgenstein, Habermas, Schutz, Piaget e Ricoeur, bem como as fundamentações pragmáticas de Mead e Peirce para refutar as con-

cepções positivistas da teoria da verdade como correspondência e da objetividade mitificada que desvalorizavam a comunicação e a ação humana na construção social da realidade. Para tanto, também buscou-se aplicar na metodologia científica uma valorização da pesquisa qualitativa como ferramenta de pesquisa necessária ao entendimento da Comunicação conforme a epistemologia do paradigma construtivista de ciência.

Palavras-chave: Comunicação; ciência; ideologia; linguagem.
\end{abstract}

\begin{abstract}
This article is a critical-interpretive re- tic conceptions of the theory of truth as view trying to establish a relationship correspondence and mythical objectivity between Communication and Science, that devalued the communication and hubased on some characteristics common to man action in the social construction of both human manifestations as the reali- reality. For this, also aimed to apply scization of language and opaque / ideolo- entific methodology in an appreciation of gical character, using criticism views of qualitative research as a study tool necesWittgenstein, Habermas, Schutz, Piaget sary for the understanding of communiand Ricoeur, as pragmatic foundations of cation as the epistemology of constructiMead and Peirce to refute the positivis- vist paradigm of science.
\end{abstract}

Keywords: Communication; science; ideology; language. 


\section{Introdução: Para pensar a opacidade da comunicação}

$\mathrm{O}$ estudo da comunicação sob a perspectiva crítica da Filosofia da Linguagem surge com os estudos de Ludwig Joseph Johann Wittgenstein, mas se desenvolve com as contribuições de Jürgen Harbermas.

Segundo Danilo Marcondes (2000), Wittgenstein vai pensar uma linguagem como prática social concreta, mas acaba deixando de pensar uma teoria da linguagem que esteja integrada a uma teoria da sociedade que situe o papel dessa linguagem, uma teoria da ideologia que explique as distorções no uso da linguagem através de formas de dominação na sociedade e da maneira como essa dominação é reproduzida e justificada. "A preocupação de Wittgenstein é essencialmente analítica, voltada para o desenvolvimento de um instrumento de análise, a partir do uso concreto da linguagem e suas interações que o uso de seus termos e expressões envolvem e pressupõe". (Marcondes, 2002: 110).

A filosofia wittgensteiniana, então, se apresenta como uma superação do cientificismo ao reconhecer a importância dos conhecimentos compartilhados pelo ordinary people no mundo da vida. No entanto, é criticada exatamente por propor uma análise do significado de expressões a partir de seu uso comum em contextos determinados, o que teria feito Wittgenstein deixar de lado análises fundamentais à própria essência da linguagem.

O significado se daria través dos jogos de linguagem ${ }^{1}$, que seria os conjuntos heterogêneos da linguagem, com suas regras, convenções e finalidades próprias. Sendo muitos e variando de acordo com o contexto de uso em que os empregamos (para indagar, consolar, indignar-se ou descrever etc.), os jogos de linguagem seriam determinantes para elucidação do significado. Para

1. Wittgenstein traça uma analogia entre a noção de linguagem e a noção de jogo. Há diversos tipos de jogos: jogos de tabuleiro, jogos de cartas, competições esportivas, etc. Mas não há uma essência dos jogos. Um jogo de cartas apresenta semelhanças com os jogos de tabuleiros, mas também muitas diferenças; se compararmos esses últimos com os jogos de bola, surgirão outras semelhanças e outras se perderão. O que há é uma sobreposição de traços que Wittgenstein chama de semelhança de família. Numa família, alguns partilham a mesma cor do cabelo, outros partilham a mesma estatura, outros o tom de voz, etc. Mas geralmente não há característica que esteja presente em todos os membros da família. O mesmo ocorre com o conceito de "jogo". Chamamos práticas muito diferentes de "jogo" não porque haja uma definição exata que esteja implícita em todas as aplicações do termo, mas porque essas diversas práticas manifestam semelhança de família (Durante, 2013). Semelhantemente, as diversas práticas linguísticas são reunidas sob a denominação de "linguagem" em virtude de suas semelhanças de família. 
Comunicação, Ideologia e Ciência: questões epistemológicas e

saber, pois, o que significa uma palavra, a melhor estratégia seria descrever os traços mais evidentes desse jogo e revelar qual é o papel desempenhado pela palavra em questão (Wittgenstein, 2000).

Mas é aí que essa Filosofia da Linguagem incorre no mesmo problema que o da Semântica Formal: enquanto esta última afasta-se da linguagem tal como é usada, não sendo capaz de produzir nenhuma elucidação sobre o significado; a primeira não tematiza, em sua origem, o caráter opaco da linguagem em uso, produzindo, ambas, um conceito artificial, pois se não reconhecermos que a linguagem como uma forma de interação social, estruturadora da experiência, refletindo e reproduzindo as estruturas sociais e, portanto, as desigualdades, os conflitos, a manipulação etc., então estaremos igualmente trabalhando com um conceito de linguagem que marginaliza elementos essenciais de sua natureza (Marcondes, 2000).

Para transpor essa fragilidade do conceito, a Filosofia da Linguagem há de ter uma perspectiva mais crítica (estabelecendo mesmo uma metodologia crítica de análise), tematizando de alguma forma a questão da ideologia (caráter social), e não apenas se limitar às analises da linguagem em uso e a utilizar conceitos como contexto, convenção, falante/ouvinte etc.

É então que a Teoria da Ação Comunicativa, de Jürgen Habermas desenvolve esse conceito, interpretando a linguagem como objeto socialmente construído, como prática social concreta que reflete a estrutura da interação social. Assim se faz necessária uma análise das condições constitutivas do discurso possível. Essa análise parte de um conceito de linguagem como comunicação que se funda na noção de intersubjetividade: o uso da linguagem consiste em um ato de entendimento mútuo, levando necessariamente a um acordo fundamentado, justificado, ao qual se chega através do diálogo, através da possibilidade de se retomar, interrogar o discurso (Marcondes, 2000).

Marcondes (2000) explica que, para o autor alemão, nosso uso linguístico concreto é caracterizado por distorções nesta situação ideal, originárias da própria estrutura social, havendo desigualdades na distribuição dos papéis linguístico-sociais, nas regras do discurso e em seu controle. Estas distorções geram casos em que a situação ideal é fictícia, embora pareça real, as justificativas são apenas aparentes, os falantes apenas imaginam que controlam as regras. É dessa forma que se caracteriza linguisticamente a "manipulação ideológica". 
Por isso, conforme Habermas (1997), a importância de se formular uma situação ideal de linguagem: para distinguir o falso consenso do verdadeiro, em nome da qual se interpreta o discurso da manipulação ideológica, para fundamentar uma metodologia crítica e não apenas descritiva.

Essa metodologia crítica é feita a partir da Ação Comunicativa, de um conceito de interação visando o entendimento a cerca de uma situação compartilhada.

Primeiro, considera-se a natureza dialógica da linguagem, em que se reconstrói o discurso em geral (a rede principal de interações linguísticas) como um jogo que tem como um lance inicial uma tomada de posição do falante e tem como lance de resposta uma contraposição de seu interlocutor, sendo a regra do jogo a validação ou justificação dos lances. Assim a identidade do falante não pode ser considerada como originária e sim como formada, constituída como capacidade de realizar atos de fala, isto é, como tomadas de posição no jogo da linguagem. Os falantes se auto-identificam, portanto, através da realização de um ato de fala como tomada de posição (Marcondes, 2000).

Sobre o processo de identificação dos falantes/ouvintes, Marcondes detalha:

Essa identificação é aceita pelos ouvintes quando reconhecem a autoidentificação dos falantes. O consenso se produz na medida da capacidade de identificação recíproca entre falante e ouvinte. O pressuposto fundamental desse consenso é a existência de regras reconhecidas de justificação e validação dos lances. Dessa forma, a identidade do falante e do ouvinte pressupõe uma identidade coletiva do grupo social que aceita as regras e do qual ambos fazem parte (Marcondes, 2000: 116).

Neste trecho, o autor explicita como a Teoria da Ação de Habermas colabora para o desenvolvimento de uma Teoria Crítica da Filosofia da Linguagem: a partir dessa identidade dos falantes duplamente constituída (em primeiro lugar, como identidade convencional - coletiva -; em segundo, como identidade individual - a partir da possibilidade de recorrer à regras no uso da linguagem, o falante pode tomar a universalidade pretendida por toda regra de justificação para a interpretação de regras particulares -). 
Comunicação, Ideologia e Ciência: questões epistemológicas e metodológicas

Dessa forma, uma proposta crítica deve supor que, em algum momento e de alguma forma, existe a autonomia da razão individual. Deve considerar visões de mundo e formas de ação alternativas de realizar atos de fala (Marcondes, 2000).

\section{Intersubjetividade: a linguagem se concretizando enquanto comunicação}

Sobre a duplicidade e o consenso na construção da identidade dos falantes em um processo comunicativo, Rüdiger (2009) vai explicar que o sentido também remete analiticamente à orientação recíproca, que guia a conduta dos indivíduos dentro de certas condições; é uma propriedade intersubjetiva presente de um modo ou de outro, em maior ou menor grau, na conduta social, ainda que transcenda a consciência imediata.

Analogicamente, para Pierce, a comunicação entre locutor e auditor exige um "fundamento" ou "território" comum entre os interlocutores, para que possa concretizar-se, e este aspecto do universo partilhado acaba por remeter diretamente para a questão da fixação intersubjetiva do valor e moldura semântica dos termos de qualquer conversação. Além disso, uma situação interlocutiva é sempre inter, mas também intra-dialógica, devido ao aspecto de indeterminação ou vagueness da comunicação, que remete sempre para sucessivas reelaborações mentais no âmbito do processo de semiose ilimitada em que todo o sujeito se encontra envolvido (Gradim, 2011).

Em Schutz, há também um movimento de percepção que avalia o compartilhamento intersubjetivo de significados e o processo de significação, de objetificar conceitos (uma concepção da natureza humana e da sua relação com o mundo da vida que privilegia a intersubjectividade) como condições para que a linguagem se concretize enquanto comunicação, a qual "desempenha um papel estruturante nas manifestações concretas de sociabilidade" (Correia, 2004: 11).

Ainda tratando do caráter social da linguagem, Schutz apontava para uma abordagem que levaria em consideração não apenas o caráter intersubjetivo, mas também intencional que se dá na ação comunicativa.

João Carlos Correia (2004: 159) afirma que Schutz discute a comunicação como um tipo de ação que se dirige a outro com a intenção de dar a conhecer um significado. Ou seja, a ação comunicativa é uma ação social porque é dotada de significado subjetivo e dirigido a outros. Para além do significado 
que a mensagem carrega, existe um motivo para comunicar que ultrapassa esse significado. "A confusão com qualquer outra ação significativa é, pois, possível, porque toda a ação externa de tipo social apresenta um significado subjetivo que lhe é atribuído pelo ator, neste caso pelo falante". Porém, não permite que se dissolva o conceito de ação comunicativa no conceito de ação dotada de significado. "A intencionalidade na transmissão dos significados surge como o elemento essencial e característico dos processos comunicativos". Neste sentido, o comunicador não espera apenas uma compreensão do seu interlocutor, mas uma tomada de posição, uma atitude, conduta que é condicionada por essa compreensão e orientada para ela. "A comunicação é sempre finalista: espera sempre produzir um determinado efeito na pessoa a quem se dirige".

Essa propriedade intencional que faz parte da essência da comunicação, pensado por outros autores já citados como o caráter opaco, ideológico, também é ora analisado na comunicação enquanto da ciência.

\section{A opacidade também da Ciência}

Habermas (1968), analisando estudos de Hebert Marcuse, em "Técnica e Ciência como Ideologia", oferece um panorama pensado por seu colega de escola frankfurtiana e uma alternativa de superação de suas considerações que já apontavam para o caráter ideológico da ciência.

Marcuse foi inspirado pelo conceito de racionalização de Max Weber, que definia a ampliação das esferas sociais submetidas aos critérios de decisão racional. A isso correspondia à industrialização do trabalho social e como consequência a influência desses critérios de ação instrumental (critérios de decisão racional) em outras instâncias da vida (urbanização nas formas de existência, tecnificação do tráfego e da comunicação). Neste caso, a racionalização progressiva da sociedade depende da institucionalização do progresso científico e técnico. É então que Marcuse se convence de que naquilo que Weber chamou de racionalização não se implanta uma racionalidade, mas uma forma de dominação política oculta. Sobre essa forma de dominação, Habermas (1968), esclarece:

A racionalidade deste tipo só se refere à correta eleição entre estratégias, à adequada utilização de tecnologias e à pertinente instauração de sistemas (em situações dadas para fins estabelecidos), ela subtrai o 
entrelaçamento social global de interesses em que se elegem estratégias, se utilizam tecnologias e se instauram sistemas, a uma reflexão e reconstrução racionais. Essa racionalidade estende-se, além disso, apenas às situações de emprego possível da técnica e exige, por isso, um tipo de ação que implica dominação; quer sobre a natureza ou sobre a sociedade. A ação racional dirigida a fins é, segundo a sua própria estrutura, exercício de controles (Habermas, 1968: 46).

Assim, direcionando o conceito de ideologia para o caráter de ocultação da realidade e de dominação, segundo as análises de Habermas sobre a obra de Marcuse (o qual já se inspirara em Weber), a própria definição de razão técnica é, inclusive, ideológica. Portanto, não só aplicação da técnica em si mas também é dominação metódica, científica, calculada e calculante (sobre a natureza e sobre o homem).

Determinados fins e interesses de dominação não são outorgados à técnica apenas «posteriormente» e a partir de fora - inserem-se já na própria construção do aparelho técnico; a técnica é em cada caso, um projeto histórico-social; nele se projeta o que uma sociedade e os interesses nela dominantes pensam fazer com os homens e com coisas. Um tal fim de dominação é «material» e, neste sentido, pertence a própria forma da razão técnica (Habermas, 1968: 47) ${ }^{2}$.

Aqui já se deixava claro que a própria Ciência, enquanto reconhecida apenas pelo seu caráter técnico-racional, carregava desde a sua definição elementos ideológicas. Mais adiante, Habermas vai reconhecer em Marcuse, que o peculiar fenômeno de dominação nas sociedades capitalistas industriais avançadas tende a perder suas características de exploração e opressão, e torna-se "racional", sem perder o caráter ideológico político. Há então um entendimento sobre uma nova forma de legitimação da dominação: a referência à crescente produtividade e ao crescente domínio da natureza. Habermas (1968: 49) chega a afirmar que "hoje a dominação eterniza-se e amplia-se não só mediante a tecnologia, mas como tecnologia; e esta proporciona a grande legitimação ao poder político expansivo, que assume em si todas as esferas da cultura".

2. Trecho analisado por Habermas a partir da obra "Industrialisierung und Kapitalismus", de autoria de Max Webers, em Kultur und Gesellschaft, II, Francoforte, 195. 
O autor alemão relaciona a partir de então a técnica com a ação racional com respeito a fins e a partir daí, começa a enxergar um caráter também emancipador dessa técnica; pois que, ao lado da ação instrumental, Habermas vai pensar a coexistência de uma ação comunicativa e junto com ela as mutações emancipadoras do marco institucional entre questões técnicas e questões praticas. Habermas (1968) elucida:

A racionalização ao nível do marco institucional só pode levar-se a cabo no meio da interação linguisticamente mediada, a saber, pela destruição das restrições da comunicação. A discussão pública, sem restrições e sem coações, sobre a adequação e a desiderabilidade dos princípios e normas orientadoras da ação, a luz das ressonâncias socioculturais do progresso dos subsistemas de ação racional dirigida a fins - uma comunicação deste tipo em, todos os níveis dos processos políticos e dos processos novamente politizados de formação da vontade, é o único meio no qual é possível algo assim como a «racionalização» (Habermas, 1968: 88).

Para o autor (1968), uma racionalização que fosse avaliada pelas modificações através do decrescente grau de repressividade, do decrescente grau de rigidez e da aproximação a um tipo de controle de comportamento que permita a distinção de papéis e uma aplicação flexível das normas internalizadas, não leva a um incremento do poder de disposição técnica sobre os processos objetivados da natureza e da sociedade; mas sim geraria uma racionalização das normas sociais que dotaria os membros da sociedade com oportunidades mais amplas de emancipação e de uma progressiva individuação.

Assim, unindo o caráter opaco da linguagem, presente também na Comunicação e na Ciência, abre-se um parêntese neste artigo para se apostilar sobre outras nuances que o termo ideologia traz consigo.

Antes mesmo de configurar um aspecto negativo do conceito, ideologia deve ser entendida aqui também como pressuposto das relações vivenciadas pelo homem, e como tal, pode e deve ser alterada, modificada, reinventada, forjada. Dessa forma, as relações experimentadas e modificadas, oferecem, por conseguinte, os instrumentos necessários para uma constante mudança da sociedade, possibilitando sair da condição de dominação, mesmo que através de uma emancipação parcial e gradativa pressuposta numa busca aproximativa da universalidade. Ideologia assume um caráter não só de dominação (tam- 
bém, mas não só), de encobrimento do real, mas de processualidade para a autonomia dos sujeitos.

Em se tratando da natureza da relação entre ciência e ideologia, segundo Paul Ricoeur (1996), esta depende tanto do sentido que possamos dar ao conceito de ciência quando ao sentido que podemos estabelecer quando nos referimos à ideologia.

De fato, pensar que não se pode fazer crítica à ideologia simplesmente porque estamos situados em posições também ideológicas, pode parecer ingênuo e sem sustentação. Ricoeur (1996) vai dizer que o pesquisador que não possui pressuposições, não coloca questões, e quem não coloca questões não pode formular hipóteses e, ao mesmo tempo, nada mais procura.

Ocorre aqui com o pesquisador, o mesmo que se dá nas sociedades: as ideologias são distâncias, discordâncias referentes ao curso real das coisas. Mas a morte das ideologias constituiria a mais estéril lucidez. Porque um grupo social sem ideologia e sem utopia seria sem projeto, sem distância em relação a si mesmo, sem representação de si. Seria uma sociedade sem projeto global, entregue a uma história fragmentada em acontecimentos inteiramente iguais e, por conseguinte, insignificante (Ricoeur, 1996: 89).

Aqui o autor chama atenção para o caráter relacional e relativo da ideologia, sem torná-la relativista. Ressitua o conceito pensado parcialmente para apresentar um pensamento mais global. Somente quem estiver inteiramente consciente do alcance limitado de todo ponto de vista, encontra-se no caminho da compreensão procurada do todo (Mannheim apud Ricoeur, 1996: 90).

Dessa forma, o autor francês aponta algumas proposições sobre a relação ciência - ideologia. A primeira delas diz respeito a relação de pertencimentos que todos os humanos prescindem e que jamais poderão refletir inteiramente sobre isso, porque sua fala sempre vai denunciar um lugar, um contexto. Pretender isso, arriscar-se-ia cair na armadilha do absoluto e não é essa a intenção ao se falar de ideologia, quanto mais de ideologia num sentido mais críticoneutro.

Antes de qualquer distância crítica, pertencemos a uma história, a uma classe, a uma nação, a uma cultura, a uma ou a tradições. Ao assumir essa pertença que nos precede e nos transporta, assumimos o primeiro 
papel da ideologia, o que descrevemos como função mediadora da imagem, da representação de si. Pela função mediadora das ideologias, também participamos das outras funções: funções de dissimulação e de distorção. Todavia, sabemos agora que a condição ontológica de pré-compreensão exclui a reflexão total que nos colocaria na situação privilegiada do saber não-ontológico. (Ricoeur, 1996: 92).

Ainda segundo ele, não dá para se pensar os intelectuais sem amarras ou pontos de apoio, mas estes precisam continuar a ser "transportados por aquilo que Hegel chamou de substância ética". A ideologia seria então o código de interpretação da ciência. Complementando o pensamento, outras proposições sugeridas por Ricoeur (1996: 92) dizem respeito à autonomia dos sujeitos. "Se o saber objetivante é sempre segundo relativamente à relação de pertença, não obstante, pode constituir-se numa relativa autonomia".

Com efeito, o autor acaba aferindo na ciência o caráter ideológico, sob o viés do contexto histórico e social. "Nada nos é mais necessário, em nossos dias, que a renúncia à arrogância da crítica, para empreendermos, com paciência, o trabalho incessantemente retomado do distanciamento e do assumir de nossa condição histórica"(Ricoeur, 1996: 95).

\section{A Ideologia Social e a Ideologia Epistêmica}

Jean Piaget e Garcia (2011) fazem uma refutação categórica da presunção positivista da avaloratividade científica, ao observar a influência exercida pela ideologia social na definição do aparelho conceitual e do conjunto de teorias que constituem a ciência aceita em determinado momento histórico e num mesmo quadro epistêmico, direcionando a pesquisa científica. Neste sentido chamam a atenção para fato de que algumas linhas de pesquisa destacam-se e outras encontram pouco ou nenhum apoio, enquanto alguns temas tornam-se moda em detrimento de outros.

Neste sentido, salientam Piaget e Garcia (2011: 337) que a definição das linhas de pesquisa sofre estímulos ou pressões de setores sociais: é o caso da tecnologia aplicada à indústria, "cujo desenvolvimento ocasionou descobertas fundamentais que abriram novos campos de pesquisa científica. A tecnologia militar tem sido talvez o exemplo mais característico”. 
É possível imaginar que, se os estímulos tivessem sido diferentes, outros campos da ciência poderiam ter sido objeto de uma maior atenção por parte dos melhores pensadores do nosso tempo, outras descobertas teriam sido realizadas e outras teorias científicas teriam nascido para explicá-las. Um grande setor do conhecimento científico continua assim a ampliar-se, não de forma estritamente racional, respondendo a uma problemática interna, mas de um modo algo arbitrário e graças a um conjunto de disposições orientadas por exigências externas impostas pela sociedade. É por isso que designamos o tipo de paradigma assim condicionado por "paradigma social" (Piaget; Garcia, 2011: 337 - 338).

Assim, pode-se constatar que a decisão de investir tantos esforços em energia nuclear e não em reconversão da energia solar é uma decisão a favor de alguns temas de pesquisas em virtude de suas aplicações práticas não por razões ligadas a uma concepção particular de natureza epistêmica (Piaget; Garcia, 2011: 338 - 339).

Por outro lado, Piaget e Garcia identificam um outo tipo de ideologia (a ideologia epistêmica) na determinação da aceitação ou rejeição de conceitos ou temas cujo caráter "científico" é negado ou exaltado num determinado momento histórico estritamente por não se adequarem ao ou reproduzirem o aparelho conceitual que a comunidade científica considera como o único válido.

A mecânica de Newton só foi aceita na França após trinta anos. (...) Algumas décadas mais tarde, as explicações “à Newton” eram não só universalmente aceitas, como tinham se tornado o próprio modelo da explicação científica (Piaget; Garcia, 2011: 339).

Desta maneira, evidencia-se a influência deste tipo de paradigma que não se impõe de fora a partir de normas socialmente estabelecidas, mas constitui a maneira natural de aceitação para todo indivíduo que pretenda produzir e ter a sua produção considerada legítima na comunidade dos investigadores científicos num determinado período, sem imposição externa explícita.

É uma concepção que se tornou parte integrante do conhecimento aceito e que com ele se transmite tão naturalmente quanto se transmite a linguagem falada ou escrita de uma geração a outra. É assim que propomos designar esse tipo de paradigma como um "paradigma epistêmico" 
em oposição ao "paradigma social” descrito anteriormente (Piaget; Garcia, 2011: 339).

\section{Pragmática, Teoria Consensual da Verdade e Comunicação}

Com George Mead a Comunicação se liberta da condição menor de mero instrumento para satisfação de interesses particulares do sistema da estrutura de poder a que a Mass Communication Research a diminuiu. A Teoria da Comunicação de Mead reconhece na comunicação o fator distintivo da humanidade diante das demais espécies do reino animal, quando o ser humano, no seu desenvolvimento filogenético, deixou de realizar a sua integração através de gestos e sons para vivenciar uma integração social baseada em símbolos de significado idêntico, ou seja através da intercompreensão comunicativa. Esta concepção se constituiu num passo decisivo para superação da filosofia da consciência no sentido da filosofia da linguagem.

A pragmática é uma corrente filosófica iniciada por Peirce que presta especial atenção à relação entre os signos e os seus utilizadores, compreendendo que, para além das dimensões sintática e semântica na análise do processo sígnico, há uma dimensão contextual, a qual evidencia que o signo não é independente da sua utilização.

A novidade da abordagem pragmatista da semiose está em não remeter a utilização dos signos para uma esfera exclusivamente empírica, sóciopsicológica, mas encarar essa utilização de um ponto de vista lógicoanalítico. A dimensão pragmática é tal como as dimensões sintática e semântica da semiose uma dimensão lógica" (Fidalgo, 1998: 90).

Na perspectiva pragmática, - a validade de uma teoria deve ser medida pela sua adequação para resolução de problemas práticos do mundo da vida, sem se restringir às questões exclusivamente teóricas - "a validade de uma teoria consiste apenas numa adequação à prática. Pragmatismo significa positivamente, neste sentido, a percepção lúcida dos problemas e a capacidade prática de os resolver sem preocupações de ordem teórica" (Fidalgo, 1998: 45).

Mas qual o significado originário que C. S. Peirce atribuiu ao termo 'pragmatismo'? Esse significado pode encontrar-se no artigo de Peirce 'Como tornar as nossa ideias claras' de 1878 . O pragmatismo tal como 
Comunicação, Ideologia e Ciência: questões epistemológicas e

transparece da máxima pragmatista formulada aí por Peirce é sobretudo um método lógico de clarificação das ideias. O significado originário de pragmatismo é de natureza lógica (Fidalgo, 1998: 46).

No desenvolvimento de sua reflexão, Peirce começa por questionar a noção cartesiana de clareza, ponderando que, nesta tradição lógica iniciada por Descartes, clareza significa a capacidade de reconhecer uma ideia em qualquer circunstância que ela ocorra e nunca a confundir com nenhuma outra, o que apresenta dois problemas. O primeiro diz respeito ao fato de que esta capacidade é sobre-humana, uma vez que ninguém pode representar uma ideia que seja reconhecida em todos os contextos e em todas as formas em que ela surgisse, não duvidando nunca de sua identidade, o que seria incorrer numa presunção similar à da teoria positivista da verdade como correspondência, que também implica uma universalidade completa, uma verdade absoluta. $\mathrm{O}$ segundo é que esse reconhecimento não seria mais do que uma "familiaridade com a ideia em causa. Neste caso, porém, teríamos um sentimento subjetivo sem qualquer valor lógico. A clareza de uma ideia não pode resumir-se a uma impressão" (Fidalgo, 1998: 46).

A teoria da verdade e da realidade é formulada por Peirce vinculando as noções de verdade e realidade à crença de uma comunidade de comunicação, onde, nos casos em que estas se mostram mal-sucedidas, a consequente dúvida vai provocar uma inquirição com o objetivo de construir uma nova crença mais evoluída num processo de semiose ilimitada. Esta concepção pioneira da teoria consensual da verdade vai se tornar a engenharia do pensamento moderno, oferecendo as bases de refutação da lógica tradicional.

Segundo Anabela Gradim (2011: 87), quando Peirce afirma ser um realista, tem em mente uma dimensão epistemológica, significando com isso que "o real existe, resiste-nos e não é uma ficção humana". Mas há um aspecto mais sutil na nova teoria da realidade peirceana, que se manifesta quando define o real como aquilo que é cognoscível a longo prazo, ou aquilo no qual a informação e o raciocínio mais cedo ou mais tarde resultarão. O real é real é assim identificado com o cognoscível e com aquilo que é representado pela comunidade na opinião final.

Para Peirce, o objeto da opinião verdadeira constitui então o real e este é exterior à mente, causando no homem a sensação e a experiência. Isso é que põe em marcha o processo de inquiry, que depois alimenta através do 
confronto das hipóteses com o real. Quando se afirma algo do real, essa proposição é verdadeira, não por causa do enunciador, mas sê-lo-á independentemente do que qualquer homem possa pensar dela (Gradim, 2011: 88).

A realidade externa que "corresponde aos nossos sentidos e sensações" é independente do pensamento de qualquer homem particular - mas não do pensamento em geral. Com isso Peirce salva a objetividade da "opinião final" da comunidade, que faz coincidir com o real - tornando a verdade e o real coincidentes com o objeto dessa final opinion. Sendo a realidade o objeto da opinião final, se esta se confinasse a um grupo particular, então as externalidades que lhe correspondessem poderiam muito bem ser concebidas pelo grupo e, em suma, seriam idealistas. Consequência imediata desta visão do real é que este não é causa, mas produto da atividade mental humana e fruto de um processo de comunicação (Gradim, 2011: 90).

Embora se convencione localizar o advento histórico da guinada linguística/pragmática na década de 60 do século XX, é imprescindível para sua adequada compreensão o reconhecimento de que a construção do paradigma científico construtivista já vinha sendo elaborada desde o século XIX, com os pragmáticos George Mead, Charles Peirce, entre outros, que foram marginalizados pela hegemonia da ideologia epistêmica de ciência positivista e sua completa subordinação à ideologia social da época, através da chamada Mass Communication Research norte-americana.

Neste contexto de obscurantismo científico, o positivismo colonizou por várias décadas a reflexão crítica e toda concepção teórica que reconhecesse o estatuto científico da comunicação como a dimensão da humanidade que a distingue das demais espécies do reino animal, bem como o empoderamento da sociedade através da possibilidade da agência humana ressignificar os conteúdos existentes na ordem institucional estabelecida e empreender a mudança social, com a gradativa emancipação dos mecanismos de dominação, repressão e violência simbólica. A grande maquinaria de ideologia epistêmica colocada em ação pelo positivismo estava baseada numa epistemologia primária, fetichizada pela ideia do acesso à verdade absoluta das leis de causa e efeito universais, e por uma metodologia restrita à rotina fática de uma pesquisa burocratizada realizada exclusivamente através dos procedimentos de mensuração das técnicas quantitativas. 


\section{Considerações Finais: A Comunicação como Ciência Qualitativa na cons- trução social da realidade}

Fechando o parêntese sobre ideologia, é mister, por fim se pensar que a Comunicação enquanto uma ciência, ambas sofrendo influências de seus caracteres opacos, não pode ser estudada apenas nos moldes quantitativos, com a finalidade de aferição e averiguação racional como pretendeu as pesquisas positivitas. A Comunicação precisa ser também tensionada como uma ciência essencialmente qualitativa e que, embora tenha sofrido severos preconceitos ao longo da história, tem sido recolocada como fator determinante nas investigações mais atuais das Ciências Sociais Aplicadas.

Ao fazer referência a um estudo qualitativo, estar-se levando em consideração o que Bauer, Gaskell e Allum (2002: 23) reconstruíram metodologicamente: "pesquisa qualitativa evita números, lida com interpretações das realidades sociais, e é considerada pesquisa soft".

Em virtude da forte predominância dos moldes positivistas de se conceber a ciência, legando às pesquisas quantitativas, por muitos anos, o topo da legitimidade racional-científica, a pesquisa qualitativa foi marginalizada e considerada apenas no estágio exploratório do processo de pesquisa, com a finalidade de explorar distinções qualitativas, a fim de se desenvolver mensurações, ou para que se tivesse certa sensibilidade com o campo de pesquisa. Entretanto, formulações mais recentes consideram a pesquisa qualitativa como igualmente importante para guiar, inclusive, a análise dos dados levantados ou mesmo para fundamentar interpretações. Agora a pesquisa qualitativa é vista como um empreendimento autônomo de pesquisa, no contexto de um programa de pesquisa com uma série de diferentes projetos (Bauer, Gaskell e Allum: 2002).

Dessa forma, mesmo uma pesquisa quantitativa não chega às suas conclusões objetiva e automaticamente, mas carece imprescindivelmente de ações qualitativas até para a escolha / exclusão de categorias, de delimitação de objetos, de procedimentos metodológicos de coletas dados, como de ações interpretativas para análise dos dados obtidos.

Segundo Bauer, Gaskell e Allum (2002):

A mensuração dos fatos sociais depende da categorização do mundo social. As atividades sociais devem ser distinguidas antes que qualquer frequência ou percentual possa ser atribuído a qualquer distinção. 
É necessário ter uma noção das distinções qualitativas entre categorias sociais, antes que se possa medir quantas pessoas pertencem a uma ou outra categoria. Se alguém quer saber a distribuição de cores num Jardim de flores, deve primeiramente identificar o conjunto de cores que existem no jardim; somente depois disso pode-se começar a contar as flores de determinada cor. O mesmo é verdade para os fatos sociais (Bauer, Gaskell e Allum, 2002: 24).

Confirmando isso, Isaac Epstein (2005: 27) afirma que todo e qualquer "procedimento quantitativo deve ser precedido por uma reflexão sobre quais os atributos pelos quais os fenômenos estudados são dessemelhantes e podem ser ignorados em relação aos objetivos pretendidos".

Destarte, quantos aos objetivos da pesquisa, Gaskell (2002) aclara:

A finalidade real da pesquisa qualitativa não é contar opiniões ou pessoas, mas, ao contrário, explorar o espectro de opiniões, as diferentes representações sobre o assunto em questão. Em um meio social específico, digamos, na profissão médica, o que nós estamos interessados em descobrir é a variedade de pontos de vista no assunto em questão, por exemplo, a homeopatia, e especificamente o que fundamenta e justifica estes diferentes pontos de vista (Gaskell, 2002: 68).

Gaskell (2002) anota que o principal objetivo da pesquisa qualitativa é apresentar uma amostra do espectro dos pontos de vista, pensados em termos sociais. Seguindo essa linda de pensamento, Bauer, Gaskell e Allum (2002) abordam o mundo, como o conhecemos e o experienciamos, isto é, o mundo representado e não o mundo em si mesmo, como algo constituído através de processos de comunicação, corroborando assim com Berger \& Luckmann. A pesquisa social qualitativa, portanto, apoiar-se-ia em dados sociais, dados sabre o mundo social, que são o resultado, e são construídos nos processos de comunicação.

Para tanto, os autores (2002) distinguem dois tipos de dados sociais - os que são construídos através de uma comunicação informal (existente na vida cotidiana, em que as pessoas espontaneamente se expressam e falam sobre o que é importante para elas e como elas pensam sobre suas ações e as dos outros) e os que são resultados da comunicação formal (que exige conhecimento especializado para seguir as regras do mercado, como o treino para escrever 
Comunicação, Ideologia e Ciência: questões epistemológicas e metodológicas

artigos de jornal, para produzir desenhos para um comercial, ou para criar um arranjo para uma banda popular ou para uma orquestra sinfônica).

Em se tratando dessa comunicação formal sob o viés construtivista, Bauer, Gaskell e Allum (2002) elucidam:

Os dados formais reconstroem as maneiras pelas quais a realidade social é representada por um grupo social. Um jornal representa até certo ponto o mundo para um grupo de pessoas, caso contrário elas não o comprariam. Nesse contexto, o jornal se torna um indicador desta visão de mundo. O mesmo pode ser verdade para desenhos que as pessoas consideram interessantes e desejáveis, ou para uma música que é apreciada como agradável. O que uma pessoa lê, olha, ou escuta, coloca esta pessoa em determinada categoria, e pode indicar o que a pessoa pode fazer no futuro (Bauer, Gaskell e Allum, 2002: 22).

Assim, pensar a Comunicação e a Ciência como elementos importantes na construção social da realidade é também analisar seus caracteres opacos, presentes inclusive na linguagem. Esse caráter opaco, estudado enquanto ideologia, pode sim atuar e operar na tentativa de estabelecer e manter relações de dominação, mas, como analisou Castro \& Rocha (2014), Eagleton (1997) e Habermas (1997), em dadas circunstâncias de crises e tomadas de consciência, pode ser uma ferramenta também de estabelecimento de uma oposição, de autonomia em relação à dominação estabelecida e algumas vezes até de reordenação das forças.

Neste sentido, como vislumbra Boaventura de Souza Santos (2001: 57), a ciência, que surgiu e se afirmou na modernidade se distinguindo do senso comum e o menosprezando, precisa agora assumir o desafio educativo, no qual também não pode prescindir da comunicação, de elevar o nível de consciência e conhecimento das massas a tal ponto de vir a se tornar senso comum.

\section{Referências Bibiográficas}

Bauer, M.W.; Gaskell, G. \& Allum, N.C. (2002). Qualidade, quantidade e interesses do conhecimento - Evitando confusões. In M.W. Bauer \& G. Gaskell (Orgs). Pesquisa qualitativa com texto: imagem e som: um manual prático. Tradução de Pedrinho A. Guareschi. Petrópolis: Vozes. 
Berger, P. \& Luckmann, T. (2003). A construção social da realidade: tratado de sociologia do conhecimento. Petrópolis: Vozes.

Castro, R. \& Rocha, H.C.L. (2014). Junho de 2013 no Brasil: O jornalismo e a ideologia. In H. Rocha, R. Castro \& A. Vizeu, Comunicação e Ideologia. Recife: PROEXT-UFPE \& Ed. Universitária da UFPE.

Correia, J.C. (2004). A Teoria da Comunicação de Alfred Schutz. Lisboa: Livros Horizonte, Colecção: Media e Jornalismo.

Corcuff, P. (2001). As novas sociologias: construções da realidade social. Rio de Mouro, Sintra.

Dijk, T.A. (2012). Discurso e poder. São Paulo: Contexto.

Durante, R.D.A. (2013). A comunicação como um jogo: sobre a dimensão lúdica como a política da diversão programada em Vilém Flusser. São Paulo: PUC. Tese de doutorado apresentada ao Programa de PósGraduação em Comunicação e Semiótica, da Pontifícia Universidade Católica de São Paulo. Disponível em: www.sapientia.pucsp.br. Acesso em: out 2014.

Eagleton, T. (1997). Ideologia: uma introdução. São Paulo: Editora da Universidade estadual Paulista.

Epstein, I. (2005). Ciência, poder e comunicação. In J. Duarte \& A. Barros (Orgs). Métodos e técnicas de pesquisa em comunicação. São Paulo: Atlas.

Fidalgo, A. (1998). Semiótica: a lógica da comunicação. Covilhã: Serviços Gráficos da Universidade da Beira Interior.

Gaskell, G. (2002). Entrevistas individuais e grupais. In M.W. Bauer \& G. Gaskell (Orgs). Pesquisa qualitativa com texto: imagem e som: um manual prático. Tradução de Pedrinho A. Guareschi. Petrópolis: Vozes.

Gradim, A. (2011). My language is the sum total of myself: universos dialógicos em Peirce. In J.M. Santos, P.M.S. Alves \& J.P. Serra, (Orgs.). Filosofias da Comunicação. Portugal, Covilhã: Editora da Universidade da Beira Interior, Livros Labcom, Série Estudos em Comunicação.

Habermas, J. (2002). A inclusão do outro: estudos de teoria política. São Paulo: Loyola. 
Comunicação, Ideologia e Ciência: questões epistemológicas e metodológicas

Habermas, J. (1997). Direito e Democracia: entre facticidade e validade. Vol II. Rio de Janeiro: Tempo Brasileiro.

Habermas, J. (1968). Técnica e Ciência como Ideologia. Lisboa: Edições 70.

Marcondes, D. (2000a). Desfazendo mitos sobre a pragmática. ALCEU, 1(1): 38-46, jul/dez. Disponível em: www.ifcs.ufrj.br. Acesso em: 28 jan 2014.

Marcondes, D. (2000b). Filosofia, linguagem e comunicação. São Paulo: Cortez Editora.

Marx, K. (1997). O 18 Brumário e cartas a Kugelmann. Rio de Janeiro: Paz e Terra.

Marx, K. \& Engels, F. (2004). A ideologia Alemã. São Paulo: Martin Claret.

Piaget, J. \& Garcia, R. (2011). Psicogênese e história das ciências. Petrópolis: Vozes.

Ricoeur, P. (1996). Interpretação e Ideologias. $4^{\mathrm{a}}$ Ed. Organização e Tradução de Hilton Japiassu. Rio de Janeiro: Francisco Alves.

Rüdiger, F. (2009). Ciência social crítica e pesquisa em comunicação: trajetória histórica e elementos de epistemologia. Porto Alegre: Gattopardo.

Serra, J.P. (2003). Informação e Sentido: o estatuto epistemológico da informação. Covilhã/Portugal: Editora da Universidade da Beira Interior, Livros Labcom.

Santos, B.S. (2001). Um discurso sobre as ciências. Porto: Edições Afrontamento, $12^{\mathrm{a}}$ edição.

Schütz, A. (2003). El Problema da realidad social. Buenos Aires: Amorrortu.

Thompson, J.B. (1995). Ideologia e cultura moderna: teoria social crítica na era dos meios de comunicação de massa. Petrópolis: Vozes, 1995.

Wittgenstein, L. (2000). Investigações filosóficas. São Paulo: Ed. Nova Cultural (Col. Os Pensadores - trad.: José Carlos Bruni). 